\title{
Baropodometer as a Clinical Tool for Evaluating and Following Treatment of Postural Deviations - A Case Report
}

\author{
Cordeiro $\mathrm{TL}^{1,2^{*}}$, Duarte $\mathrm{A}^{2}$, Collucci $\mathrm{A}^{2}$ and Frade $\mathbf{M}^{1,3,4}$ \\ ${ }^{1}$ Graduate Program in Internal Medicine, FMRP - USP, Brazil \\ ${ }^{2}$ Clinical Collucci Physical Therapy and Rehabilitation, Ribeirão Preto - SP Brazil \\ ${ }^{3}$ Dermatology Division, FMRP-USP, Brazil \\ ${ }^{4}$ National Reference Center of Sanitary Dermatology of the School Hospital, FMRP-USP, Brazil
}

*Corresponding author: Thania Loiola Cordeiro, Graduate Program in Internal Medicine, FMRP - USP, Clinical Collucci - Rua São José, 1788 - Ribeirão Preto/SP, Brazil, Tel: 5516 36258325; E-mail: thania.cordeiro@gmail.com

Rec date: May 15, 2014, Acc date: Jul 28, 2014, Pub date: Aug 01, 2014

Copyright: (C) 2014 Cordeiro TL, et al. This is an open-access article distributed under the terms of the Creative Commons Attribution License, which permits unrestricted use, distribution, and reproduction in any medium, provided the original author and source are credited.

\begin{abstract}
The pre-pubertal age can be considered as the most important for prevention and treatment of postural deformity. Postural adjustments to maintain static and dynamic balance depend on the relationship between sensory input organs (captors) and the environment. Currently, there are three captors known: the eye, the vestibule and the soles of the feet. Postural insoles work as exteroceptors and aim to reorganize the muscle group's tone and influence the body posture by proprioceptive reflexes and subsequent correction. Besides the proprioceptive insoles, the Pilates method for spine treatment and postural deviations has been widely applied, and it presents great adhesion and good outcomes for school children and pre-teens. The baropodometric projection of the body center of pressure (COP) could be used in clinical practice as an evaluation tool in the treatment of postural dysfunctions and spinal deviations, through a baropodometer device, but little has been published about its clinical outcomes on everyday use. This study described the case of an 11 year old with pelvic deviation due to short leg length and the treatment chosen accordingly to a baropodometric evaluation, such as the use of postural insoles combined with Pilates sessions for 40 days. After this period, it was noted a better plantar surface and peak pressures distribution, as well as a more homogeneous weight bearing on both feet, which can induce improvements on postural behavior and prevents spinal injuries.
\end{abstract}

Keywords: Postural balance control; Baropodometry; Proprioceptive insoles; Pilates

\section{Introduction}

The pre-pubertal age can be considered as the most important for prevention and treatment of postural deformity [1]. In childhood and adolescence, the posture is in development process, and therefore more susceptible to future problems, depending on the locomotors adaptation to maintain body balance within the mechanical conditions imposed [1]. This might lead the child to adopt bad posture habits in their 6-10 years old. So it can be state that, at this stage the child could acquire postural defects arising from the behavior and social relations [2].

Postural adjustments to maintain static and dynamic balance depend on the relationship between sensory input organs (or captors) and the environment [3]. Currently, there are three captors known: the eye, the vestibule and the soles of the feet [2].

Posturology is a technique for evaluation and treatment of postural disorders according to the interaction of the feet with the ground through proprioceptive insoles created in 1980 by Bordiol [4]. These postural insoles work as exteroceptors and aim to reorganize the muscle group's tone and influence the body posture by proprioceptive reflexes and subsequent correction [3]. Furthermore, the authors state that these insoles reduce plantar pressure peaks by redistributing the reaction force from the ground to the feet [4]. The use of postural insoles is an innovative technical aid to the population, and despite being a common clinical practice there are few studies about its use [5]. This technique is based on the action of very fine rubber pieces that are placed between the insole and the skin and thus stimulates mechanoreceptors in the chosen region performing a minimal deformation by small reliefs, which provides information to the postural system. In response, the Central Nervous System produces postural rebalancing through the tonic muscle reflex reactions and corrects postural imbalances [3]. There are specific plantar regions whose stimulation causes a reorganization of postural body tone. These stimuli may act at a distance, correcting any unevenness of the upper limbs, iliac crests and/or generating symmetry in paraspinal muscle tension $[4,6]$.

Besides the proprioceptive insoles, the Pilates method for spine treatment and postural deviations has been widely applied, and it presents great adhesion and good outcomes for school children and pre-teens [7]. This technique advocates the improvement of agonist and antagonist muscle relations, favoring the work of stabilizing muscles [8].

The body balance maintenance is also achieved by the postural control system, and the action of sensory and motor nerves that play this role. These are required to ensure the vertical projection of the body's center of gravity (CG), which is supposed to be maintained within the base of support (polygon delimited by the lateral edges of the feet) giving stability to the body and allowing the execution of various transactions with its upper segments. The Body Center of 
Pressure (COP) constitutes the neuromuscular response to changes or accelerations of the CG and can be measured by a pressure plate [9-11]. This device captures the risk areas of the foot, comparing the results of treatments performed over time. It also assists the clinician for the preparation of plantar orthoses [12]. The baropodometric projection of the COP could be used in clinical practice as an evaluation tool in the treatment of postural dysfunctions and spinal deviations. According to Bienfait [13], any deformation of the feet will require an adaptation of the postural system and vice versa. Thus, it is believed that the assessment, and the monitoring of treatment with baropodometry might be of clinical and academic relevance. Thus, the following study describes a case where baropodometry was decisive to the continuation of the treatment. It is important to notice that the use of baropodometry in clinical practice for assessing postural treatment combining the Pilates method with the use of proprioceptive insole was not found in the literature.

\section{Case Report}

Patient presenting 11 years, male, eutrophic, BMI 21.2, attended at Clinica Collucci - Ribeirão Preto looking for physiotherapy care, complaining of asymptomatic thoracic asymmetry (according to the parents of the child). Postural analysis revealed elevation of the right posterior superior iliac crest, and pelvis rotated in a counterclockwise direction, with protrusion of the right shoulder. The patient also presented with supination of the left hind foot during the swing phase of the gait. This postural assessment was enhanced by baropodometry (ISP equipment Informatique pressure plate Footwork model, with an active surface plate $40 \times 40 \times 0.5 \mathrm{~cm}$, with the patient standing barefoot with arms along the body, and the look to the horizon for 30 seconds. This exam showed displacement of the total body center of pressure (COP) of the patient to the right, along with the absence of left midfoot support (cavus foot), and higher plantar peak pressure under the metatarsal heads on both right and left feet (Figure 1A).

The choice of the treatment technique relied on the suspicion of lower limbs discrepancy, and an examination of the patient's Orthoradiography presenting the left leg shorter by $0.5 \mathrm{~cm}$ confirmed the diagnosis. Therefore, we proposed the use of a proprioceptive insole with postural elements and that vary between 0.3 and $0.2 \mathrm{~cm}$ positioned as to stimulate specific displacement of the posterior and lateral plantar COP points as well as the relaxation of the intrinsic muscles of the left midfoot. Besides the proprioceptive insole, we recommended Pilates sessions to improve the patient's positioning of the pelvis and diminishes lower muscular asymmetry already installed, due to the leg discrepancy. Unfortunately, the only radiographic exam available and allowed by the patient's parents was the Orthoradiography at the time of the study.

After 40 days of insole usage and 16 sessions of Pilates, a new Baropodometric assessment was performed, this time with improved left midfoot support and centralization of the COP, along with the displacement of the maximum peak plantar pressure to the rearfoot, on both right and left feet (Figure 1B).

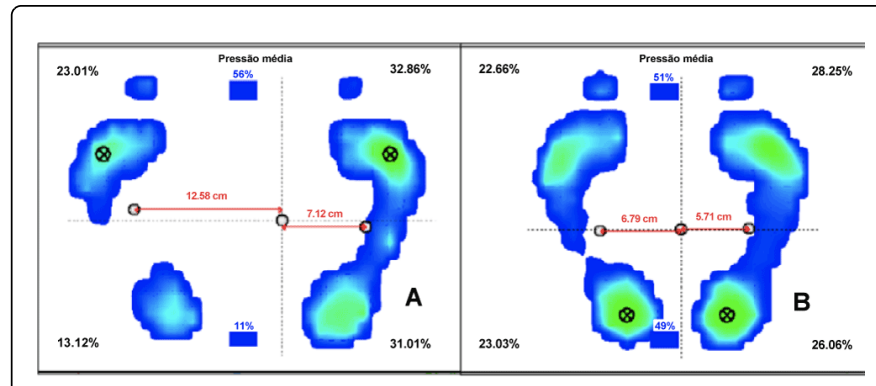

Figure 1: A: Static baropodometry taken before the start of treatment; 1B: Static baropodometry taken after 40 days of use of the insole and 16 sessions of Pilates

Parameters such as the average value for plantar peak pressure, the distribution of body weight bearing and total surface area of plantar support were also assessed before, during, and after the 40 days of insole usage and 16 Pilates sessions. As a result, we found that all these parameters were more homogeneous in their distribution of right and left feet by the end of the study (Figures 2-4).

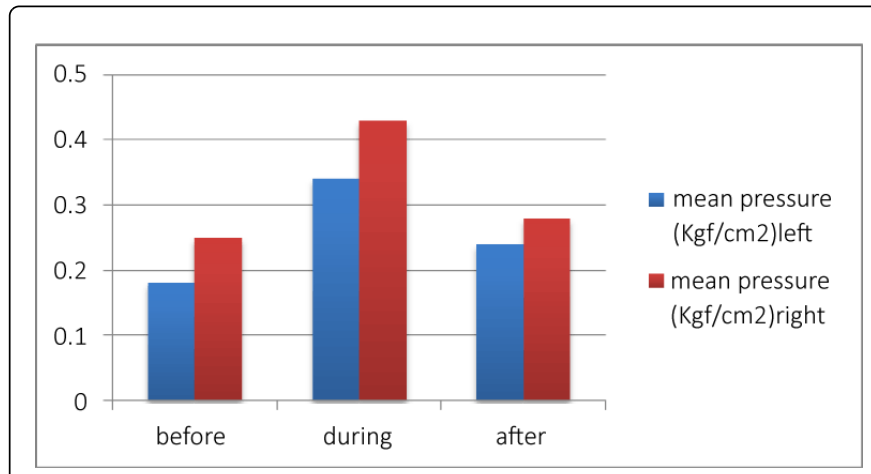

Figure 2: Average plantar peak pressures on left and right feet before, during and at the end of 40 days of treatment.

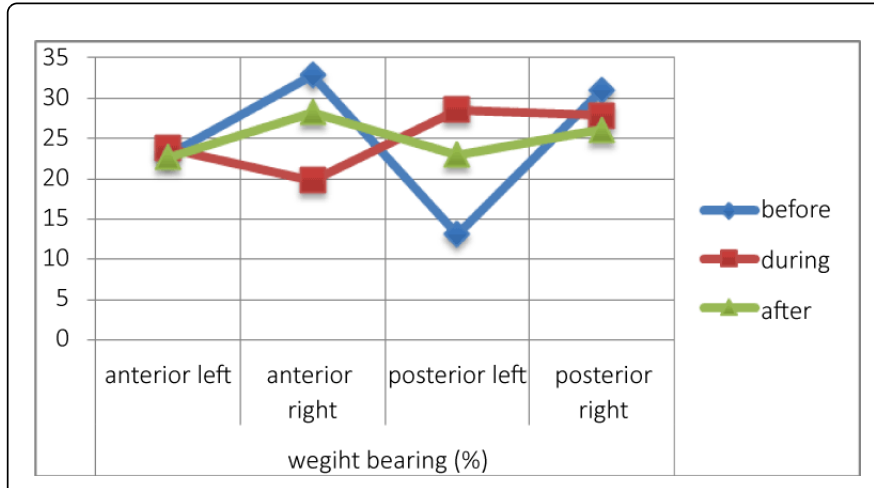

Figure 3: Percentage of weight bearing on the right and left foot with respect to the front and rear quadrants before, during and after 40 days of treatment. 


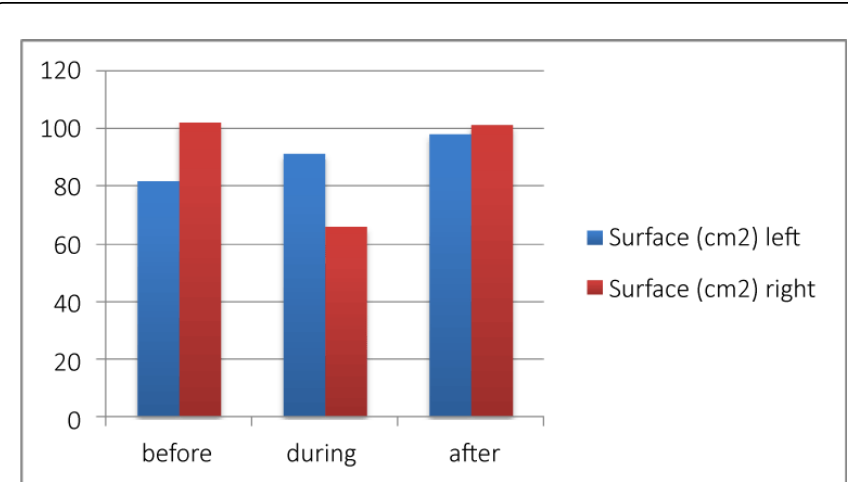

Figure 4: Total area of plantar support before, during and after 40 days of treatment

\section{Discussion and Conclusion}

An anatomical short leg occurs when there is an actual length difference in the bony components of the lower limb. A structurally short limb is often compensated by a functional adaptation on the long leg side, including ankle pronation. The anterior and posterior iliac crests are lower on the side of the short leg, unless foot positioning compensates for the difference [14]. To maintain the body balance in case of leg discrepancy of up to $1.5 \mathrm{~cm}$, pelvis might tilt or performs oblique rotation on its axis [15]. This small discrepancy is found in between 40 and $70 \%$ of the adult population, which may adopt other strategies for maintaining balance, damaging the spinal alignment and posture in general [16].

Since the body balance maintenance can be measured through the displacements of the COP, we used an electronic baropodometer to objectively estimate the parameters of load distribution in orthostatic conditions as well as the pressure peaks and the total plantar contact area with the ground.

For this case study we proposed the use of proprioceptive insole with postural elements and shims that vary between 0.3 and $0.2 \mathrm{~cm}$ positioned to stimulate a specific displacement of the posterior and lateral plantar COP points as well as the relaxation of the intrinsic left midfoot muscles.

Besides the proprioceptive insole, Pilates sessions were recommended for the patient to improve stretching and tone of the muscles belonging to the posterior chain [17], mainly soleus and hamstrings, since they exhibited asymmetry resulting from the discrepancy of the lower limbs [18].

The Pilates method was developed during the First World War, to rehabilitate injured soldiers. Recently, it has been used by health professionals with the aim of integrating body and mind, to offer better physical conditioning, flexibility, strength, balance and body awareness. All six principles of the Pilates method were applied to this case study subject: Breathing with the activation of the multifidus and transversus abdominal muscles; stabilizing exercises for the spine and hip; body awareness exercises including guidelines for organization of the cervical, thoracic spine and shoulder blades; exercises to improve mobility of the segmental spine; training of the pelvic floor; passive stretching and/or assets of the muscle groups worked more or overloaded [19]. There is controversy as to the time required by the Pilates method practice to promote balanced relationship of agonists and antagonists of the lumbar spine [20]. It is speculated to take at least six months of treatment for lower back pain relief but one study has shown that Pilates is effective in the treatment of subjects with chronic low back pain, and needed only four weeks to reduce pain intensity [8].

Brischini [21] believes that the school age is ideal to recover spinal dysfunctions effectively; after this period, the prognosis may become more difficult and the treatment more prolonged [22].

After 40 days of insole usage and 16 sessions of Pilates, baropodometry new assessment was performed, and this time presented with improvement of left midfoot support and centralization of the COP, as well as the displacement of the maximum peak plantar pressure to the rearfoot both to the right and to the left feet (Figure 1B). This result was decisive for further treatment, and safety for the parents, who sought physical therapy for correction, but particularly the prevention of postural disorders in the patient, who still continues on treatment as to this date.

According to the results revealed by baropodometry it can be inferred that the combination treatment was effective in improving the standards of plantar support, which later might be reflected in postural alignment after a longer follow-up. Besides, it is important to notice that this study might open new possibilities for a reliable and noninvasive clinical tool for evaluation and follow up for postural treatment.

However, a larger sample and longer follow-up could be suggested to determine whether this combination treatment is effective on a population.

\section{References}

1. Bruschini S, Nery CAS (1995) Aspectos ortopédicos da obesidade na infância e adolescência. In: Fisberg, M. Obesidade na infância e adolescência. São Paulo: BYK.

2. Nedel SS (2009) Efeitos das Palmilhas Posturais sobre a Postura Corporal de Escolares. Programa de Pós-Graduação em Ciências do Movimento Humano (Dissertação de Mestrado). Porto Alegre.

3. Bricot B (2001) Posturologia. São Paulo: Icone.

4. Salgado ASI, Prysiezny WL (2006) Manual de Podoposturologia. Reeducação postural através de palmilhas. Brusque: Laboratório de Posturologia do Cefit - Hospital Evangélico de Brusque.

5. Mattos HM (2006) Análise do equilíbrio postural estático após o uso de palmilhas proprioceptivas. Programa de Pós-Graduação em Bioengenharia da Universidade do Vale do Paraíba (Dissertação de Mestrado) São José dos Campos.

6. Ceci LA, Salgado ASI, Przysezny WL (2004) Modificação das Aferências sensitivas podais e sua influência na amplitude. Rev. Fisio. Magazine.

7. Segura DCA, Nascimento FC, Chiossi CA, Silva MAA, Guilherme JH, et al. (2011) Estudo Comparativo Do Tratamento Da Escoliose Idiopática Adolescente Através Dos Métodos De RPG. Revista Saúde e Pesquisa.

8. Conceição JS, Mergener CR (2012) Eficácia do método Pilates no solo em pacientes com lombalgia crônica. Relato de casos. Rev Dor. São Paulo 13: 385-388.

9. Lafond D, Duarte M, Prince F (2004) Comparison of three methods to estimate the center of mass during balance assessment. J Biomech 37: 1421-1426.

10. Zatsiorsky VM (1998) Kinematics of human motion. Champaign, IL: Human Kinetics.

11. Rubira APFA, Martins MFE, Dente CBS, Gerling NG, Tomas C, et al. (2010) Eficiência da Estabilometria e Baropodometria Estática na Avaliação do Equilíbrio em Pacientes Vestibulopatas. Neurobiologia.

12. Arkipelago (2014) Baropodômetro Eletrônico: Programa Footowork. 
Citation: Cordeiro TL, Duarte A, Collucci A, Frade M (2014) Baropodometer as a Clinical Tool for Evaluating and Following Treatment of Postural Deviations - A Case Report. J Spine 3: 175. doi:10.4172/2165-7939.1000175

Page 4 of 4

13. Bienfait M (2000) As Bases da Fisiologia da Terapia Manual. São PauloSP: Editora Summus.

14. McCaw ST, Bates BT (1991) Biomechanical implications of mild leg length inequality. Br J Sports Med 25: 10-13.

15. Walsh M, Connolly P, Jenkinson A, O'Brien T (2000) Leg length discrepancy--an experimental study of compensatory changes in three dimensions using gait analysis. Gait Posture 12: 156-161.

16. Betsch M, Wild M, Große B, Rapp W, Horstmann T (2012) The effect of simulating leg length inequality on spinal posture and pelvic position: a dynamic rasterstereographic analysis. Eur Spine J 21: 691-697.

17. Campignion P (2003) Aspectos Biomecânicos - Cadeias Musculares e Articulares - Método GDS - Noções Básicas. São Paulo: Summus.
18. Phrompaet S, Paungmali A, Pirunsan U, Sitilertpisan P (2011) Effects of pilates training on lumbo-pelvic stability and flexibility. See comment in PubMed Commons below Asian J Sports Med 2: 16-22.

19. Adams MA (2004) Biomechanics of back pain. Acupunct Med 22: 178-188.

20. Araújo MEA, Silva EB, Vieira PC, Samária Ali, Cader SA, et al. (2010) Redução da dor crônica associada à escoliose não estrutural, em universitárias submetidas ao método Pilates. Motriz, Rio Claro.

21. Bruschini S (1998) Ortopedia Pediátrica. (2nd edn) São Paulo: Atheneu.

22. Kavalco TFA (2000) Manifestação de alterações posturais em crianças de primeira a quarta séries do ensino fundamental e sua relação com a ergonomia escolar. Rev Bras Fisioterapia. 